
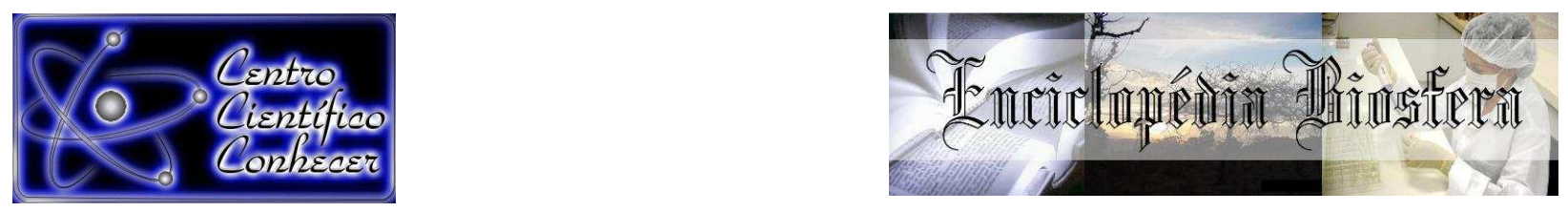

\title{
COMPARAÇÃO ENTRE MÉTODOS NA ESTIMATIVA DA ÁREA FOLIAR DE PASSIFLORAS SSP (PASSIFLORACEAE)
}

Rosimara Barboza Bispo ${ }^{1}$; Catiane dos Santos Braga ${ }^{1}$ Danielle Vieira Rodrigues ${ }^{1}$; Valdecir Göttert ${ }^{2}$; Sérgio Alessandro Machado Souza ${ }^{3}$.

${ }^{1}$ Graduanda do Curso de Licenciatura e Bacharela em Ciências Biológicas, Universidade do Estado de Mato Grosso, Campus Universitário, Alta Floresta, MT, Brasil. E-mail: rosimara.barboza@hotmail.com

${ }^{2}$ Mestre em Biodiversidade e Agroecossistemas Amazônicos, Universidade do Estado do Mato Grosso, Campus de Alta floresta, MT, Brasil.

${ }^{3}$ Professor Doutor, Programa de Pós em Biodiversidade e Agroecossistemas Amazônicos, Universidade do Estado do Mato Grosso, Campus de Alta floresta, MT, Brasil.

Recebido em: 08/04/2017 - Aprovado em: 10/06/2017 - Publicado em: 20/06/2017 DOI: 10.18677/EnciBio_2017A31

\section{RESUMO}

A área foliar pode ser uma ferramenta muito importante na avalição do crescimento e da produtividade das plantas. É de importância estudos que visem obtenção de resultados para a fundamentação de estudos fisiológicos, como crescimento da planta, intercepção de luz, eficiência da fotossíntese e resposta a fertilização, que são obtidos através da determinação da área foliar. Tendo em vista esta importância objetivou-se comparar a eficiência de dois métodos na determinação da área foliar em seis espécies de Passiflora, via dimensões foliares pelo integrador de área foliar LI-COR 3100 e imagens digitalizadas via scanner com auxílio do software ImageJ. Para as análises foram coletadas 100 folhas de cada uma das seis espécies. Os dados da área foliar foram submetidos à análise de regressão $\left(R^{2}\right)$ e como análise complementar, foi utilizado o coeficiente de correlação de Person (r). As análises estatísticas foram executadas pelo programa GENES. Na regressão o critério que obteve o melhor modelo em função da área foliar foi o coeficiente de determinação linear onde $p$ foi significativo a $1 \%(p>=0,01)$. As espécies que apresentaram maior coeficiente de determinação foram; Passiflora cristalina e Passiflora foetida ambas com $R^{2}=0,99$. O coeficiente de correlação $\left(r^{2}\right)$ também foi maior para essas duas espécies, 0,9961 $P$. cristalina e 0,9998 $P$. foetida. Conclui-se que os dois métodos se mostraram eficientes na estimativa da área foliar para as seis espécies de Passiflora e que o método alternativo de imagens digitalizadas via scanner se mostrou eficiente comparado com o método tradicional

PALAVRAS-CHAVE: espécies silvestres, ImageJ, scanner

\section{COMPARISON BETWEEN METHODS IN THE ESTIMATION OF THE FOLIAR AREA OF PASSIFLORAS SSP (PASSIFLORACEAE)}

\footnotetext{
ABSTRACT

Leaf area can be a very important tool in the evaluation of plant grow and productivity. Of importance is studies that aim to obtain results for the foundation of 
physiological studies, such as plant growth, light interception, photosynthesis efficiency and response to fertilization, which they obtained by determining the leaf area. In view of this importance, the objective of this study was to compare the efficiency of two methods in the determination of leaf area in six Passiflora species, via leaf dimensions by the leaf area integrator LI-COR 3100 and images scanned by scanner using ImageJ software. For the analyzes 100 leaves of each of the six species were collected. The leaf area data obtained were submitted to regression analysis (R2) and as complementary analysis, was utilized the correlation coefficient of Person ( $r$ ). The statistical analyzes were performed by the GENES program. In the regression the criterion that obtained the best model according to the leaf area was the coefficient of linear determination where $p$ was significant at $1 \%(p>=0.01)$. The species with the highest coefficient of determination were; Passiflora cristanila and Passiflora foetida with $\mathrm{R}^{2}=0,99$. The correlation coefficient (r2) was also higher for these two species, $0,9991 P$. cristalina and $0,9998 P$. foetida. It was concluded that the two methods were efficient in the estimation of the leaf area for the six Passiflora species and that the alternative method of digitized images via scanner was efficient compared to the traditional method.

KEYWORDS: wild species, ImageJ, scanner

\section{INTRODUÇÃO}

A área foliar pode ser uma ferramenta muito importante na avaliação do crescimento e da produtividade das plantas (LIMA et al., 2012) uma vez que a avaliação do estado nutricional das cultivares é feito normalmente pela análise foliar (MALAVOLTA et al., 1997). Os estudos para compreensão da fisiologia do crescimento das culturas requerem a estimativa da área foliar ao longo de todo o ciclo de cultivo (JADOSKI et al., 2012) bem como estudos que visem avaliar a área foliar em plantas sob diferentes condições ambientais, pois várias ações ecológicas podem afetar, de diferentes modos e intensidade, o crescimento, desenvolvimento, reprodução e a sobrevivência dos vegetais, esses estudos contribuem significativamente para o entendimento da relação planta-ambiente (MORAES et al., 2013). No maracujazeiro a determinação da área foliar possibilita fundamentação aos estudos ecológicos, como o crescimento da planta, a intercepção de luz, a eficiência fotossintética a evapotranspiração e a resposta a fertilizantes (BLANCO \& FOLLEGATTI, 2005).

Existem vários métodos de determinação de área foliar, sendo os mais utilizados: métodos via discos foliares, método de dimensões foliares e o método por equipamento medidor LI-COR. O método de referência LI-COR é obtido através de um aparelho digital integrador de área, cuja teoria operacional se fundamenta no princípio de células de grade de área conhecida, apesar de este método ser bastante preciso o aparelho não é fabricado no Brasil e em função do preço nem sempre é de fácil aquisição (MARACAJÁ et al., 2008).

Entretanto novas alternativas para a estimativa da área foliar têm sido empregadas com frequência por inúmeros pesquisadores (LUCENA et al., 2010; CARVALHO et al., 2012; SANTOS et al., 2014), esses novos métodos se baseia na análise da área foliar através de câmeras fotográficas digitais e scanners, que se encontram disponíveis no mercado, a um custo bastante acessível. Esses equipamentos são promissores para trabalhos de medição de área foliar por serem portáteis mais baratos que o integrador de área foliar LI-COR 3100 e podem ser usados em determinações não-destrutivas, possivelmente com maior precisão que o método de dimensões foliares, principalmente em situações nas quais as folhas 
apresentam-se danificadas (MARROCOS et al., 2010). Para a determinação da área foliar através deste método é necessário que as imagens obtidas sejam processadas por um programa computacional específico, capaz de processar a imagem, calculando a área desejada (GODOY et al., 2007).

O presente estudo objetivou comparar a eficiência de dois métodos na análise de área foliar em seis espécies de Passiflora sendo estas: Passiflora alata, Passiflora cristalina, Passiflora edulis, Passiflora foetida, Passiflora suberosa e Passiflora morifolia, via dimensões foliares pelo integrador de área foliar LI-COR 3100 e imagens digitalizadas via scanner com auxílio do software ImageJ.

\section{MATERIAL E MÉTODOS}

O experimento foi realizado no Laboratório de Tecnologia de Sementes e Matologia da Universidade do Estado de Mato Grosso-UNEMAT, Campus Universitário de Alta Floresta. Para as análises foram utilizadas como amostra 100 folhas de cada uma das seis espécies de Passiflora, mantidas em casa de vegetação na Universidade do Estado de Mato Grosso.

Em seguida, foi estimada a área foliar das seis espécies de Passiflora $(P$. alata, $P$. cristalina, $P$. edulis, $P$. foetida, $P$. suberosa e $P$. morifolia) com o emprego do integrador de área foliar LI-COR 3100, os folíolos foram integrados ao aparelho, um a um, em ordem numérica. Para as análises da área foliar, via scanner, as mesmas folhas de cada uma das espécies foram digitalizadas com auxílio do programa GIMP em uma resolução de 300 dpi (dots per inch), sendo as imagens armazenadas em formato TIFF (Figura 1).

A



D

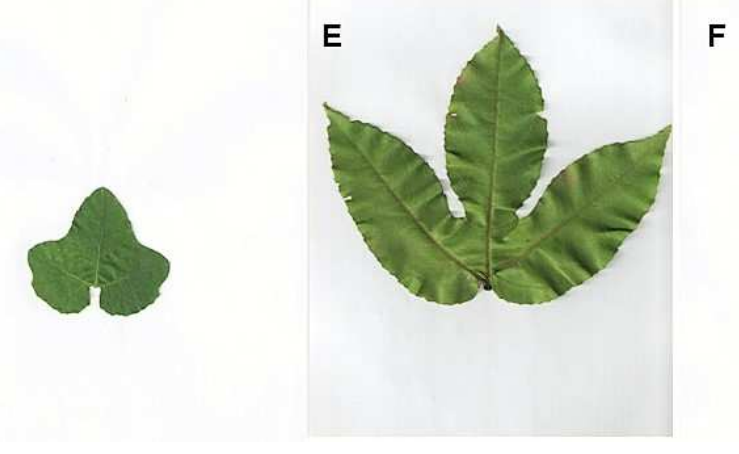

B

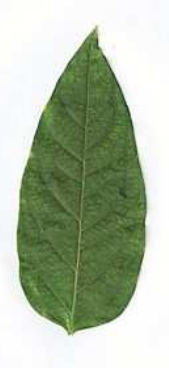

C

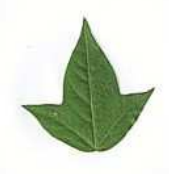

$F$

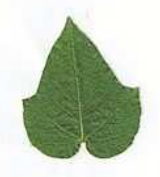

FIGURA 1- Imagens digitalizadas via scanner com auxílio do programa GIMP. A)Passiflora alata; B)P. cristalina; C) $P$. suberosa; D) $P$. morifolia; E) $P$. edulis e F) $P$. foetida. 
Através do programa ImageJ, as imagens das espécies foram obtidas de forma independente. Com o auxílio do comando Analyse/Set Scale, foi determinado o valor da escala a ser utilizado na estimativa da área foliar, e com a finalidade de obter os resultados das medidas em centímetros $(\mathrm{cm})$, atribuirão atribuir o valor 2.54 na caixa de diálogo Set Scale no iten Known distance, e a unidade $\mathrm{cm}$ em United of Length. Em seguida foi indicado a variável a ser mensurada na imagem digitalizada, através da ferramenta Analyse/Set Measurements. Na etapa seguinte foi descartado a informação de cor, Image/Type/8-bit. Posteriormente, para obter as imagens em apenas duas tonalidades, as mesmas foram binarizadas (Process/Binary/MakeBinary) (Figura 2). Após esses passos, com o auxílio da ferramenta Analyze/Analyze Particles foi marcado os itens Display Results e Clear, obtendo os valores da área foliar de cada uma das folhas das seis espécies. Os dados resultantes foram armazenados em uma planilha de dados (Excel for Windows).

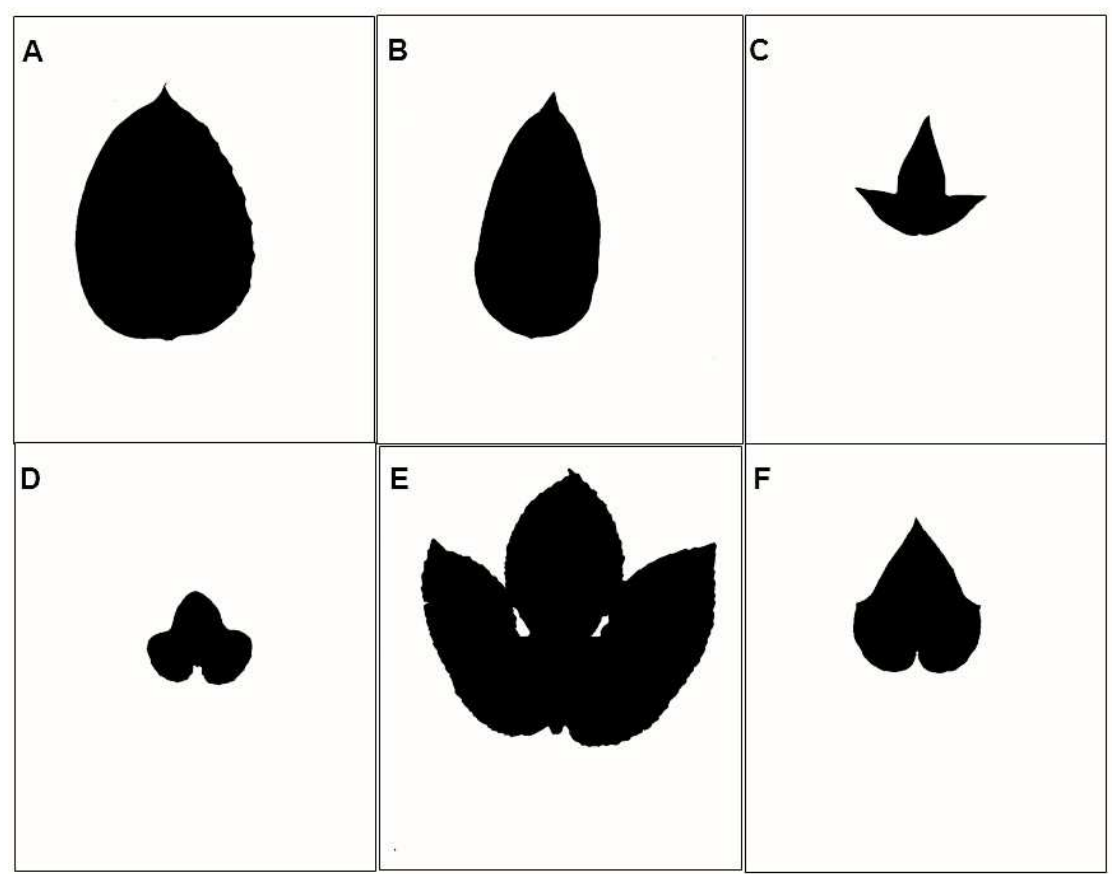

FIGURA 2 Imagens obtidas pelo editor de imagem ImageJ. A) P. alata; B) $P$. cristalina; C) P. suberosa; D) P. morifolia; E) P. edulis e F) P. foetida.

Os dados foram submetidos à análise de regressão $\left(R^{2}\right)$ utilizando-se o modelo linear $Y=a x$. $O$ valor de $Y$ estima a área foliar em função de $X$, cujos valores foram obtidos pela análise de imagens digitalizadas via scanner. Como análise complementar, foi utilizado o coeficiente de correlação de Person $(r)$ correlacionando os valores de área foliar do método via LI-COR $3100 \mathrm{com}$ os valores do método via scanner com o uso do software ImageJ. As análises estatísticas foram executadas com o auxílio do programa GENES (CRUZ, 2013).

\section{RESULTADOS E DISCUSSÃO}

Na regressão $\left(R^{2}\right)$ o critério que obteve o melhor modelo em função da área foliar foi o coeficiente de determinação linear, onde $p$ foi significativo a $1 \%(p>=$ 0,01 ), obtendo um melhor ajuste dos pontos a reta. Abaixo as representações gráficas apresentam o coeficiente de determinação $\left(R^{2}\right)$ obtidos para os dois métodos de estimativa da área foliar e para as espécies em estudo. Dentre as espécies, as que apresentaram maior coeficiente de determinação $R^{2}=0,99$ foram; 
$P$. cristalina e $P$. foetida, obtendo o ajuste satisfatório dos pontos em relação a reta (Figura 2 e 4). $P$. suberosa e $P$. morifolia obtiveram $R^{2}=0,98$ e 0.97 , respectivamente (Figura 6 e 5) e $P$. edulis $R^{2}=0,92$, sendo esses valores satisfatórios para o ajuste dos pontos a reta (Figura 3). A espécie $P$. alata obteve o menor $R^{2}=0,86$, como representado na Figura 3 , os pontos não se ajustaram perfeitamente a reta, contudo esse valor é considerado satisfatório.

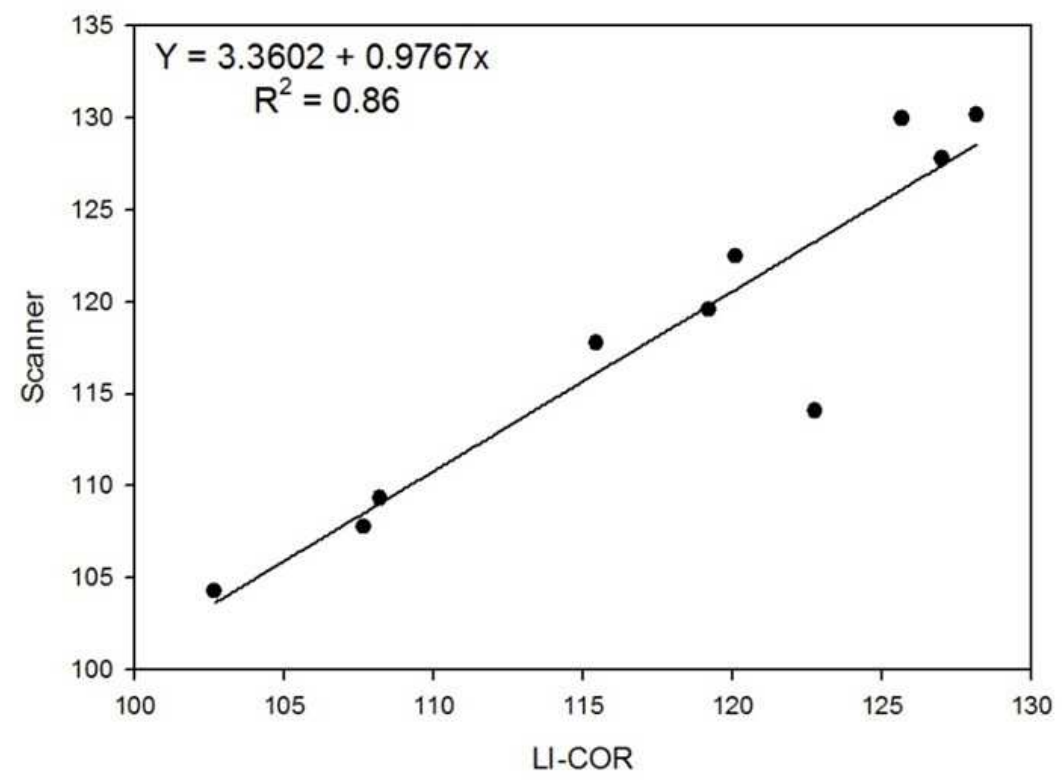

FIGURA 3-Representação gráfica da regressão linear para a área estimada das folhas de $P$. alata pelo integrador de área LI-COR e pelas imagens digitalizadas via Scanner (300dpi). No gráfico cada ponto representa a área total de 10 folhas.

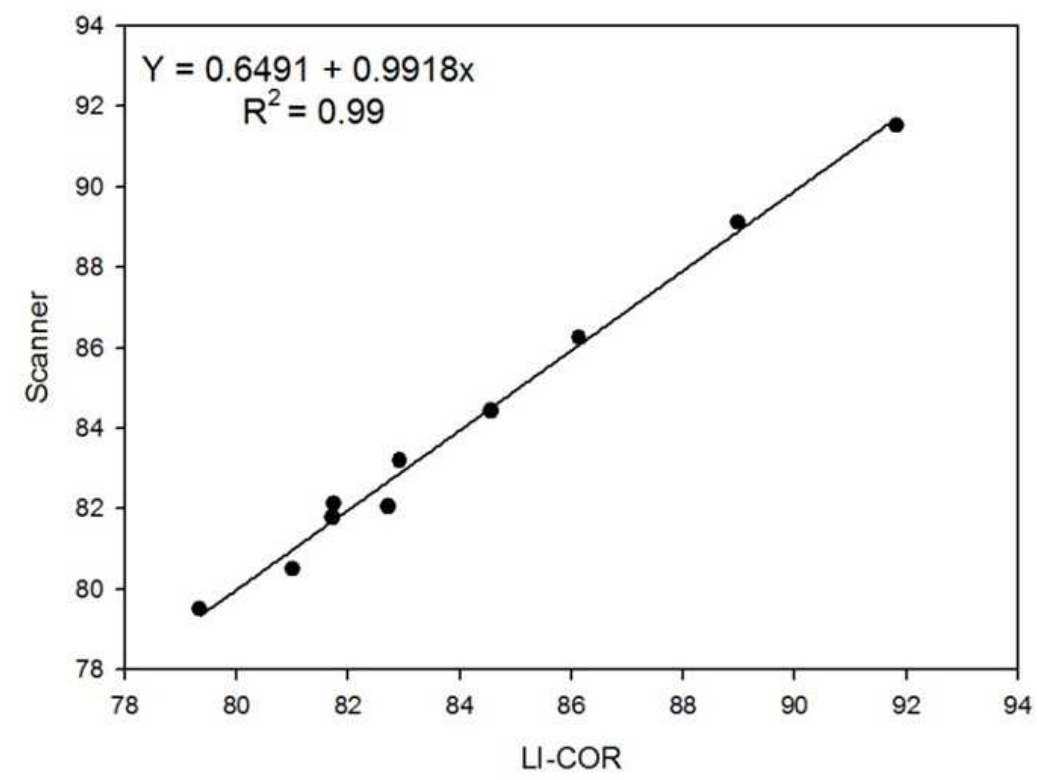

FIGURA 4- Representação gráfica da regressão linear para a área estimada das folhas de $P$. cristalina pelo integrador de área foliar LI-COR e pelas imagens digitalizadas via Scanner (300dpi). No gráfico cada ponto representa a área total de 10 folhas. 


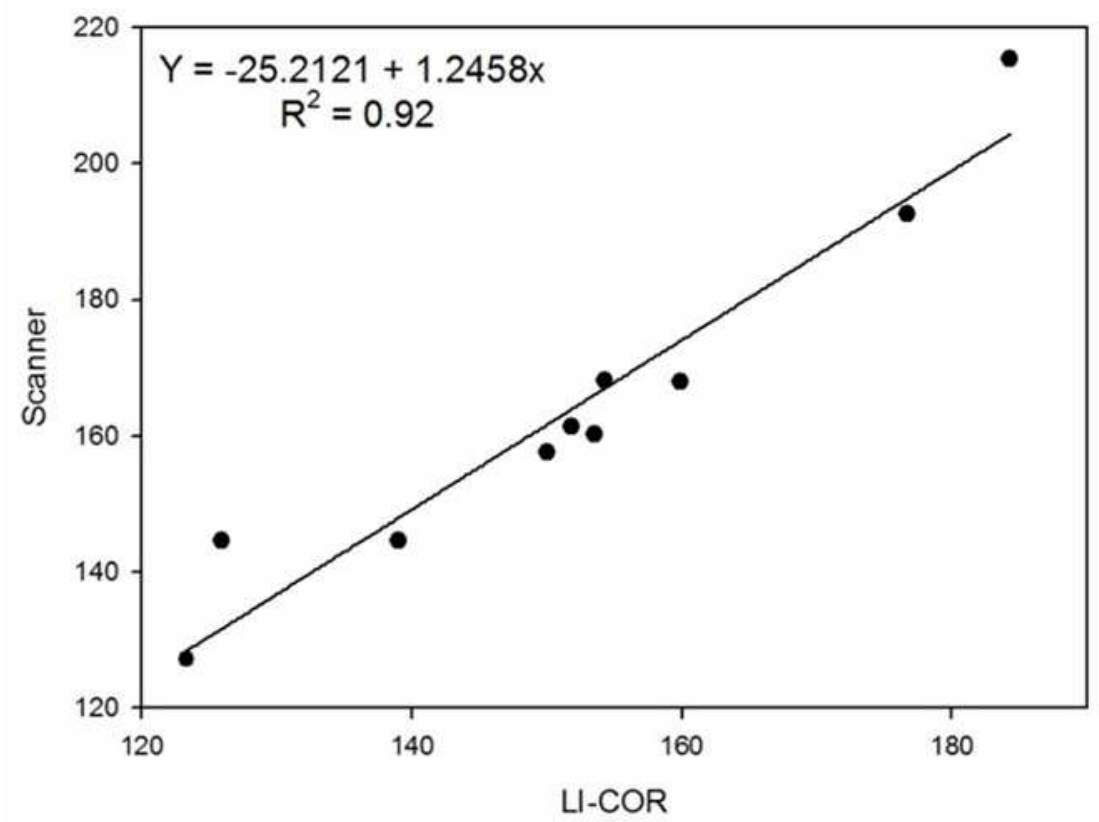

FIGURA 5- Representação gráfica da regressão linear para a área estimada das folhas de $P$. edulis pelo integrador de área foliar LI-COR e pelas imagens digitalizadas via Scanner (300dpi). No gráfico cada ponto representa a área total de 10 folhas.

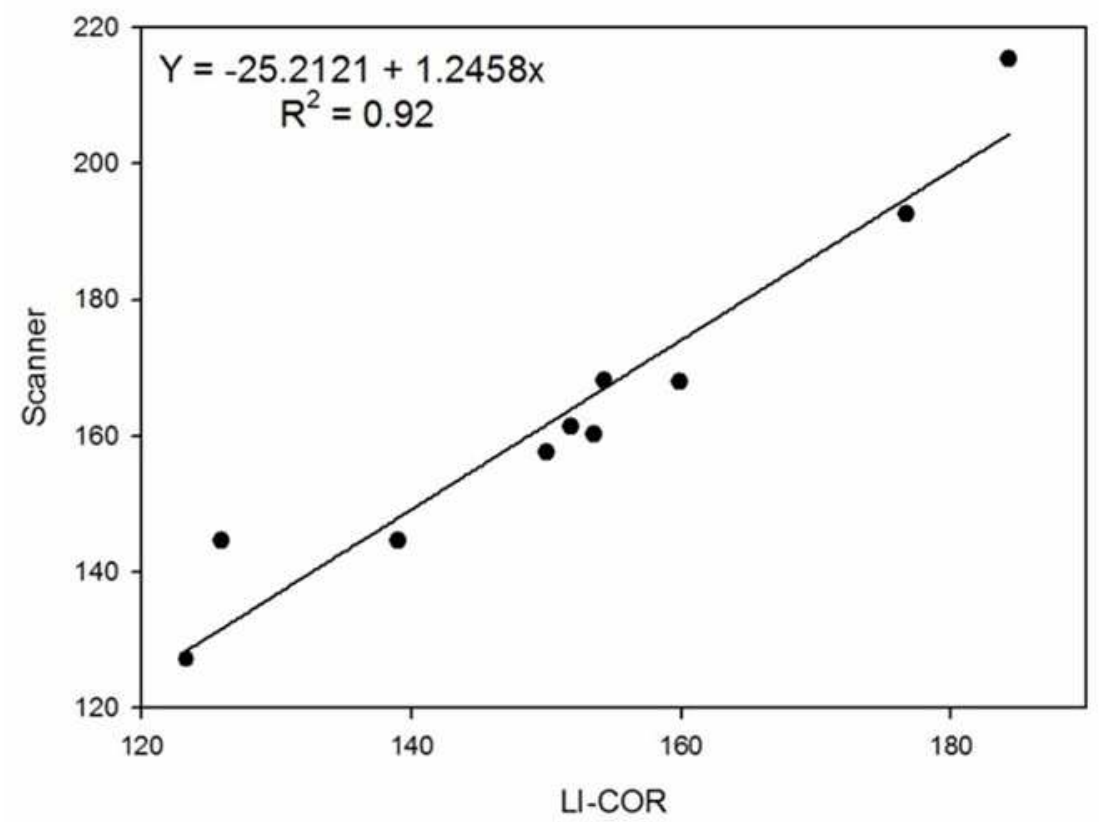

FIGURA 6- Representação gráfica da regressão linear para a área estimada das folhas de $P$. foetida pelo integrador de área foliar LI-COR e pelas imagens digitalizadas via Scanner (300dpi). No gráfico cada ponto representa a área total de 10 folhas. 


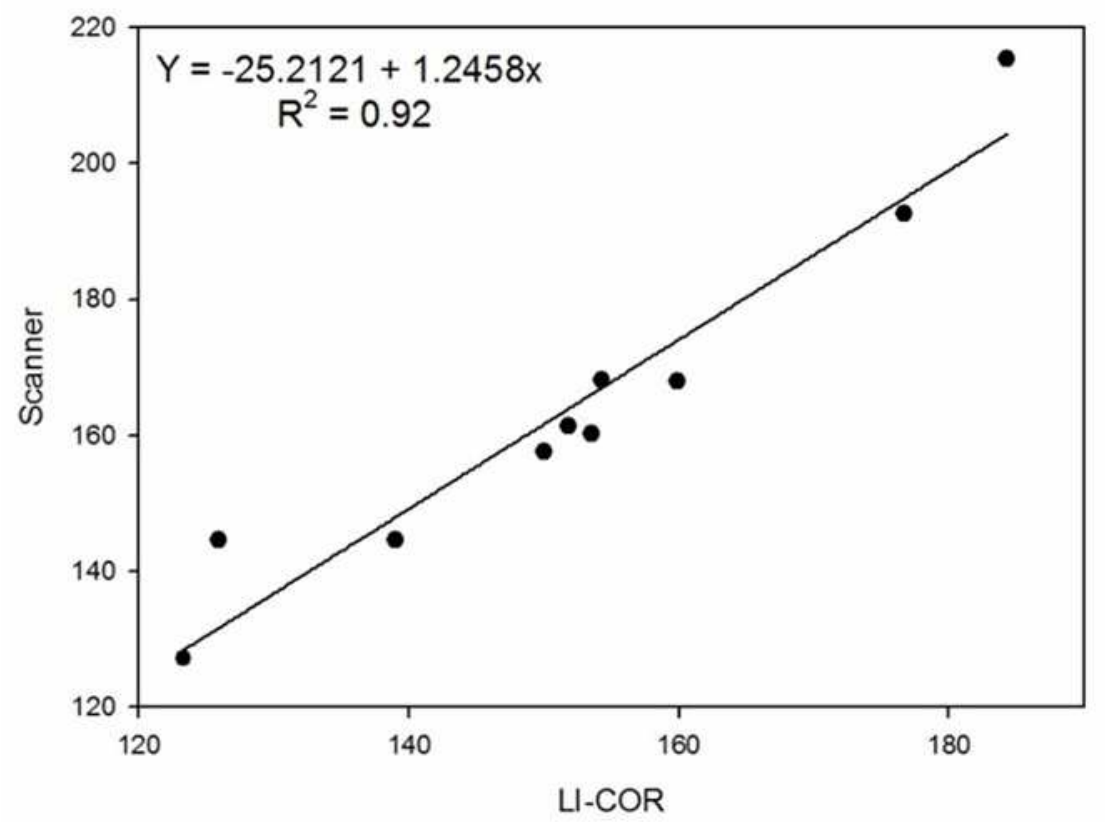

FIGURA 7- Representação gráfica da regressão linear para a área estimada das folhas de $P$. morifolia pelo integrador de área foliar LI-COR e pelas imagens digitalizadas via Scanner (300dpi). No gráfico cada ponto representa a área total de 10 folhas

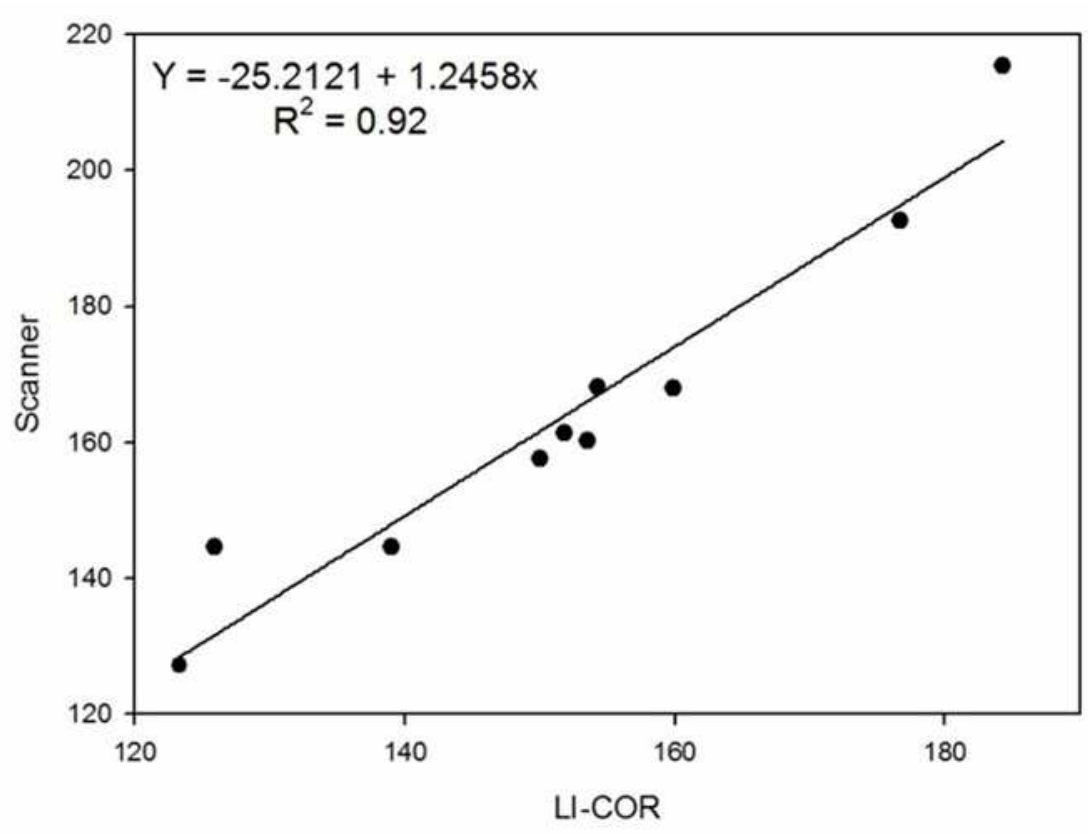

FIGURA 8- Representação gráfica da regressão linear para a área estimada das folhas de $P$. suberosa pelo integrador de área foliar LI-COR e pelas imagens digitalizadas via Scanner (300dpi). No gráfico cada ponto representa a área total de 10 folhas 
O coeficiente de correlação de Person ( $r$ ) permitiu quantificar o grau de associação entre os dois métodos de análise, onde $p$ foi significativo a $1 \%(p>0,01)$. A espécie $P$. alata obteve coeficiente de correlação $=0,9288 ; P$. cristalina $=0,9961$; $P$. suberosa $=0,9921 ; P$. morifolia $=0,9884 ; P$. edulis $=0,964$ e $P$. foetida $=0,9998$. De acordo com os valores do coeficiente de determinação $\left(R^{2}\right)$ e do coeficiente de correlação de Person ( $r$ ) pode-se inferir que esses dois critérios podem ser utilizados com eficiência para esse tipo de análise.

Em estudo PEREIRA et al., (2014) analisando o melhor modelo para a estimativa da área foliar do jambeiro vermelho obtiveram os melhores valores de $\mathrm{R}^{2}$ utilizando as equações polinomiais e lineares. FRANCISCO et al., (2014) utilizando medidas alométricas para estimar da área foliar do abacaxizeiro cv. Vitória verificaram que o melhor modelo e o mais adequado para determinar com precisão a área foliar foi o modelo linear. Em estudos semelhantes SCHMILDT et al. (2016) avaliando modelos de regressão através de medidas alométricas das folhas da espécie Passiflora edulis, através de modelos estatísticos concluíram que na regressão além do linear o modelo circunscrito também foi eficaz para estimar a área foliar da espécie.

Assim como no presente estudo a utilização do scanner como método alternativo, também se apresentou satisfatório para outros autores no desenvolvimento de suas análises. TOEBE et al., (2010) comparando os métodos de discos foliares e de fotos digitalizadas obtiveram um coeficiente de correlação de Pearson de 0,99 para a cultura de crambe (Crambe abyssinica). LUCENA et al., (2010) comparando o método de integrador de área foliar com o scanner para a cultura da aceroleira também obtiveram $R^{2}=0,97$. CARVALHO et al., (2012) para a cultura do cambuizeiro obtiveram $\mathrm{R}^{2}=0,97$ utilizando o scanner como método de referência. Em estudos Martins et al., (2013) analisando a área foliar do feijão também com auxílio do software ImageJ obtiveram bons resultados e indica a utilização deste método em substituição ao integrador de área foliar (LI-COR 3100).

De acordo com SILVA et al., (2011) a área foliar de uma cultura possui grande importância nos aspectos relacionados a produção, pois contribui para o desenvolvimento de práticas culturais, como poda, adubação, irrigação e quantificação de danos causados por patógenos. Segundo MORGADO et al., (2013), para a cultura do maracujazeiro, a área foliar afeta não somente as taxas de fotossíntese e transpiração, mas também a taxa de crescimento, qualidade e produção de frutos. Desta forma quanto maior a área foliar maior será a capacidade de absorção de luz, consequentemente maior será o ganho em produtividade da planta, garantindo também maior rentabilidade para o produtor.

A soma de todos esses estudos juntamente com os resultados do presente trabalho pode-se inferir que a análise da área foliar é de suma importância para o entendimento da fisiologia das plantas, e que o método alternativo de imagens digitalizadas via scanner para as seis espécies de Passiflora é eficiente e, portanto pode ser utilizado na estimativa da área foliar dessas espécies, uma vez que as folhas foram digitalizadas com facilidade, pois as mesmas apresentaram tamanhos proporcionais ao scanner.

\section{CONCLUSÃO}

O método alternativo de imagens digitalizadas via scanner, com auxílio do software ImageJ se mostrou eficiente na estimativa da área foliar quando comparado com o método tradicional de área foliar (LI-COR 3100) para as espécies em estudo. 
Dessa forma, o método de imagens digitalizadas se mostrou ser uma ferramenta eficiente e de baixo custo para a estimativa da área foliar.

\section{REFERENCIAS}

BLANCO, F. F.; FOLEGATTI, M. V. Estimation of leaf area for greenhouse cucumber by linear measurements under salinity and grafting. Scientia Agricola, v. 62, p. 305309, $2005 . \quad$ Disponível em; http://www.cpamn.embrapa.br/soloaguaclima/doc/Flavio/APs/AP13.pdf. DOI: 10.1590/S0103-90162005000400001

CARVALHO, D. R.; NASCIMENTO, P. G. M. L.; SILVA, M. G. O.; MESQUITA, H. C.; CUNHA, J. L. X. L. Comparação de métodos para estimativa da área foliar do Myrciaria tenella O. Berg. Agropecuária Científica no Semi-Árido, v. 8, n.4, p.0106, $2012 . \quad$ Disponível em: http://revistas.ufcg.edu.br/acsa/index.php/ACSA/article/view/220. ISSN 1808-6845.

CRUZ, C. D. GENES - a software package for analysis in experimental statistic and quantitative genetics. Acta ScientiarumAgronomy, v. 35, n. 3, p. 271-276, 2013. Disponível em: http://www.scielo.br/pdf/asagr/v35n3/v35n3a01. DOI: 10.4025/actasciagron.v35i3.21251.

FONSECA, C. E. L.; CONDÉ, R. C. C. Estimativa da área foliar em mudas de mangabeira (Hancornia speciosa Gom.). Pesquisa Agropecuária Brasileira, v. 29, n. $4, \quad$ p. 593-599, 1994. Disponível em: https://seer.sct.embrapa.br/index.php/pab/article/viewFile/4091/1382. Acesso em abril de 2017.

FRANCISCO, J. P.; DIOTTO, A. V.; FOLEGATTI, M. V.; SILVA, L. D. B.; PIEDADE, S. M. S. Estimativa da área foliar do abacaxizeiro cv. Vitória por meio de relações alométricas. Revista Brasileira de Fruticultura, v. 36, n. 2, p. 285-293, 2014. Disponível em: http://www.scielo.br/pdf/rbf/v36n2/v36n2a03.pdf. DOI: http://dx.doi.org/10.1590/0100-2945-216/13.

GODOY, L. J. G.; YANAGIWARA, R. S.; BÔAS, R. L. V.; BACKES, C.; LIMA, C. P. Análise da imagem digital para estimativa da área foliar em plantas de laranja "Pêra". Revista Brasileira de Fruticultura, v. 9 n. 3, p. 420-424, 2007. Disponível em: https://repositorio.unesp.br/handle/11449/5219.

.DOI:10.1590/S010029452007000300004.

JADOSKI, S. O.; LOPES, E. C.; MAGGI, M. F.; SUCHORONCZEK, A.; SAITO, L. R.; DENEGA, S. Método de determinação da área foliar da cultivar de batata Ágata a partir de dimensões lineares. Semina: Ciências Agrárias, v. 33, suplemento 1, p. 2545-2554, 2012. Disponível em: http://www.uel.br/revistas/uel/index.php/semagrarias/article/viewFile/8058/11754. DOI: 10.5433/1679-0359.2012v33Supl1p2545.

LIMA, R. T.; SOUZA, P. J. O. O.; RODRIGUES, J. C.; LIMA, M. J. A. Modelos para estimativa da área foliar da mangueira utilizando medidas lineares. Revista Brasileira de Fruticultura, v.34, n. 4, p. 974-980, 2012. Disponível em: http://www.scielo.br/pdf/rbf/v34n4/03.pdf. DOI: 10.1590/S0100-29452012000400003. 
LUCENA, R. R. M.; BATISTA, T. M. V.; DOMBROSKI, J. L. D.; LOPES, W. A. R.; RODRIGUES, G. S. O. Medição de área foliar de aceroleira. Revista Caatinga, v. 24, n. 2, p. 40-45, 2011.2 Disponível em: http://www.redalyc.org/pdf/2371/237117605006.pdf. ISSN: 0100-316X.

MALAVOLTA, E.; VITTI, G. C.; OLIVEIRA, S. A. Avaliação do estado nutricional das plantas: princípios e aplicações. 2.ed. Editora POTAFOS, 1997, 319 p.

MARACAJÁ, P. B.; MADALENA, J. A. S.; ARAÚJO E.; LIMA, B. G.; LINHARES, P. C. F.; Estimativa de Área Foliar de Juazeiro por Dimensões Lineares do Limbo Foliar. Revista Verde, v. 3, n. 4, p. 0-05, 2008.Disponivel em: http://www.scielo.br/scielo.php?script=sci_nlinks\&ref=000081\&pid=S0100$2945201200040000300011 \&$ lng=pt. Acesso em abril de 2017

MARROCOS, S. T. P.; DANTAS, M. S. M.; DOMBROSKI, J. L. D.; LUCENA, R. R. M.; BATISTA, T. M. V. Análise comparativa de métodos de estimativa de área foliar em beterraba. Revista verde, v. 5, n. 5, p. 140 - 146, 2010. Disponível em: http://www.gvaa.com.br/revista/index.php/RVADS/article/view/360/447. Acesso em abril de 2017.

MARTINS, T. N.; MARCHESE, J. A.; SOUZA, A. K. F.; CURTI. G. L.; FOGOLARI, H.; CUNHA, V. S. Uso do software ImageJ na Estimativa de Área Foliar para a Cultura do Feijão. Interciencia, v. 38, n. 12, p. 843-848, 2013. Disponível em: http://www.interciencia.org/v38_12/843.pdf. Acesso em abril de 2017.

MORAES, L. M.; SANTOS, R. K.; WISSERI, T. Z.; KRUPRK, A. Avaliação da área foliar a partir de medidas lineares simples de cinco espécies vegetais sob diferentes condições de luminosidade. Revista Brasileira de Biociência, v. 11, n. 4, p. 381387, 2013. Disponível em: http://www.ufrgs.br/seerbio/ojs/index.php/rbb/article/viewFile/2413/1221. ISSN 19804849 .

MORGADO, M. A.D.; BRUCKNER, C. H.; ROSADO, L. D. S.; ASSUNÇÃO, W.; SANTOS, C. E. M. Estimação da área foliar por métodos não destrutivos, utilizando medidas lineares das folhas de espécies de Passiflora. Revista Ceres, v.60, n.5, p.662-667, 2013. Disponível em: http://www.scielo.br/pdf/rceres/v60n5/09.pdf. Acesso em março de 2017.

PEREIRA, L. R.; SILVA, S. F.; CABANEZ, P. A.; MONTEIRO, E. C.; SOUZA, J. M. Modelos alométricos para estimativa da área foliar do jambeiro vermelho (Syzygium malaccense) pelo método não destrutivo. Enciclopédia Biosfera, v. 10, n. 18, p. 2239-2246, 2014.2 Disponível em: http://www.conhecer.org.br/enciclop/2014a/AGRARIAS/Modelos.pdf.

SANTOS, S. N.; DIGAN, R. C.; AGUIAR, M. A. G.; SOUZA, C. A. S.; PINTO, D. G.; MARINATO, C. S.; ARPINI, T. S. Análise comparativa de métodos de determinação de área foliar em genótipos de cacau. Bioscience Journal, v. 30, n. 1, p.411-419, 2014. http://www.seer.ufu.br/index.php/biosciencejournal/article/view/18148. ISSN 19813163. 
SCHMILDT, E. R.; NEGRIS, F. S.; CESANA JÚNIOR, E.; SCHMILDT, O.; ALEXANDRE, R. S. Equações para estimar área foliar de maracujá amarelo. Nucleus, v.13, n.1, p. 97-104, 2016. Disponível em: www.nucleus.feituverava.com.br/index.php/nucleus/article/download/1461/1946 DOI: 10.3738/1982.2278.1461.

SILVA, W. Z.; BRINATES, V. B.; TOMAZ, M. A.; AMARAL, J. F. T.; RODRIGUES, W. N.; MARTINS, L. D. Métodos de estimativa de área foliar em cafeeiro. Enciclopédia Biosfera, v. 7, n. 13, p. 746-759, 2011. Disponível em: http://www.conhecer.org.br/enciclop/2011b/ciencias\%20agrarias/metodos.pdf.

TOEBE, M.; BRUM, B.; LOPES, S. J.; FILHO, A. C.; SILVEIRA,T. R. Estimativa da área foliar de Crambe abyssinicapor discos foliares e por fotos digitais. Ciência Rural, v.40, n.2, p.475-478, 2010. Disponível em: http://www.scielo.br/scielo.php?script=sci_arttext\&pid=S0103-84782010000200036. DOI: 10.1590/S0103-84782010000200036. 